\title{
Circulating Aldosterone Levels and Disease Severity in Pulmonary Arterial Hypertension
}

Zeenat Safdar ${ }^{*}$, Aishwarya Thakur ${ }^{1}$, Supriya Singh', Yingqun $\mathrm{Ji}^{1}$, Danielle Guffey ${ }^{2}$, Charles G Minard ${ }^{2}$ and Mark L Entman ${ }^{3}$

${ }^{1}$ Division of Pulmonary, Critical Care, and Sleep Medicine, Baylor College of Medicine, USA

${ }^{2}$ Dan L. Duncan Institute for Clinical and Translational Research, Baylor College of Medicine, USA

${ }^{3}$ Division of Cardiology, Baylor College of Medicine, USA

\begin{abstract}
Objectives: It is not known whether aldosterone levels are associated with increased mortality in patients with pulmonary arterial hypertension (PAH). The primary goal of this study was to determine whether circulating aldosterone levels predict severity of PAH in terms of hemodynamic characteristics and mortality.

Methods: Patients with stable PAH were enrolled at the Baylor PH program. The plasma levels of aldosterone and BNP were measured. Clinical, hemodynamic, and outcome data was collected by chart review. Mean follow up time from study enrollment was $39 \pm 102$ months. Cox proportional hazards model was used to assess time to death.

Results: There were $125 \mathrm{PAH}$ patients with plasma aldosterone levels. Median aldosterone level was $9.9 \mathrm{pg} / \mathrm{ml}$ (25th-75th percentile: $4.1 \mathrm{pg} / \mathrm{ml}, 27.1 \mathrm{pg} / \mathrm{ml}$ ) and median brain natriuretic peptide (BNP) level was $67.5 \mathrm{pg} / \mathrm{ml}(25 \mathrm{th}$ 75th percentile: $31 \mathrm{pg} / \mathrm{ml}, 225 \mathrm{pg} / \mathrm{ml}$ ). Aldosterone levels were not significantly associated with BNP levels, six-minute walk distance, Borg dyspnea score, right ventricular systolic pressure, cardiac output and cardiac index. However, the association between aldosterone and right atrial pressure was dependent on mineralocorticoid receptor blocker treatment (Coef. $=2.88,95 \mathrm{Cl}: 1.19,4.56, \mathrm{p}=0.001)$. By log-rank statistic there was no statistical difference between the survival of patients divided by median aldosterone level $(p=0.914)$. However, there was a significant difference in patient survival between the BNP categories $(p<0.001)$ such that those with high BNP level $(>180 \mathrm{pg} / \mathrm{mL})$ had a shorter survival time.
\end{abstract}

conclusions: The aldosterone level was not associated with increased mortality in PAH but was a marker of disease severity.

Keywords: Pulmonary arterial hypertension; Aldosteron; Right ventricle; Mineralocorticoid receptor antagonist; BNP level

\section{Introduction}

Pulmonary arterial hypertension (PAH) is a disease in which increased right ventricular pressure leads to right heart failure and decreased cardiac output [1]. Neurohormonal activation by the reninangiotensin-aldosterone system (RAAS) is an important regulatory mechanism in the presence of low cardiac output associated with heart failure [2]. Aldosterone is released in response to decreased cardiac output [2,3]. Angiotensin activates aldosterone release from zona granulosa, which in turn is associated with vascular fibrosis and endothelial dysfunction [3-5]. Studies have observed that increased levels of renin and angiotensin in heart failure is related to worse mortality [6,7]. Evidence suggest that elevated plasma aldosterone levels contributes to end-organ damage as well as to cardiovascular mortality $[4,8,9]$.

Recent data suggests that hyperaldosteronism may have some predictive role in patients with PAH $[10,11]$. Based on a small number of studies, debate about the role of aldosterone as a marker of disease severity and mortality in PAH is ongoing $[2,6,10]$. Long-term data is also lacking in this area. Thus it is likely that in PAH patients, RAAS may be activated to maintain cardiovascular homeostasis. In the current study, we investigated whether circulating aldosterone levels, undertaken in an outpatient setting, can be predictive of disease severity and mortality in stable $\mathrm{PAH}$ patients.

\section{Methods}

This study was undertaken after obtaining ethics approval from Baylor College of Medicine Institutional Review Board. Consecutive patient data, which had aldosterone levels drawn as part of clinical care, was reviewed from $08 / 2000$ to $06 / 2013$. PAH diagnosis was based on standard historical right heart catheterization that showed a mean pulmonary artery pressure $\geq 25 \mathrm{~mm} \mathrm{Hg}$ and pulmonary capillary wedge pressures $\leq 15 \mathrm{~mm} \mathrm{Hg}$. Clinical, hemodynamic and laboratory data including six-minute walk distance (6MWD), medications and outcome was collected from chart review. Echocardiogram was done as part of routine clinical assessment and echocardiographer was not aware of the plasma aldosterone levels. Outcome data was collected by medical records review.

\section{Sample processing}

Aldosterone blood samples were collected from patients in supine position, between $8 \mathrm{a}$.m. and $10 \mathrm{a} . \mathrm{m}$. on the day of appointment when patient had fasted overnight. Whole blood samples were immediately centrifuged at 1200 r.p.m. for $10 \mathrm{~min}$ at $4^{\circ} \mathrm{C}$. The plasma was collected and immediately stored at $-80^{\circ} \mathrm{C}$. Aldosterone levels were determined by solid-phase radioimmunoassay. A commercially available immunoassay was used for quantitative determination of brain natriuretic peptide (BNP) levels on an ADVIA centaur analyzer

${ }^{*}$ Corresponding author: Zeenat Safdar, MD, MS, FACP, FCCP, Associate Professor of Medicine, Director, Baylor Pulmonary Hypertension Program Pulmonary-Critical Care and Sleep Medicine, Baylor College of Medicine, Houston, Texas 77030, USA, Tel: 713-798-2400; Fax: 713-798-2688; E-mail: safdar@bcm.edu

Received June 22, 2014; Accepted October 27, 2015 ; Published October 31 2015

Citation: Safdar Z, Thakur A, Singh S, Ji Y, Guffey D, et al. (2015) Circulating Aldosterone Levels and Disease Severity in Pulmonary Arterial Hypertension. J Pulm Respir Med 5: 295. doi:10.4172/2161-105X.1000295

Copyright: ( 2015 Safdar Z, et al. This is an open-access article distributed unde the terms of the Creative Commons Attribution License, which permits unrestricted use, distribution, and reproduction in any medium, provided the original author and source are credited. 
system (Siemens, Erlangen, Germany) according to the manufacture's recommendation. The normal reference level for aldosterone was $<31.0$ $\mathrm{ng} / \mathrm{dL}$ under unspecific conditions and normal BNP level range was $0-100 \mathrm{pg} / \mathrm{ml}$ at our laboratory. Aldosterone level was divided by median aldosterone level. BNP was categorized into 3 groups based on the Registry to Evaluate Early And Long-term PAH disease management (REVEAL) Registry Score Calculator: low BNP $(\leq 50 \mathrm{pg} / \mathrm{mL})$, mid BNP (51 to $180 \mathrm{pg} / \mathrm{mL}$ ), and high BNP (>180 pg/mL) [12-14].

\section{Doppler echocardiography}

All echocardiograms were obtained by registered diagnostic cardiac sonographers and interpreted by a certified cardiologist who was not aware of the patient's plasma aldosterone level. Complete echocardiogram was performed with 2-dimensional transthoracic echocardiogram (TTE) as clinically indicated using standard ultrasound equipment on the clinic day. Peak right ventricle systolic pressure (RVSP) was calculated on the basis of peak tricuspid regurgitation velocity using the following formula: $\mathrm{RVSP}=4$ (peak velocity of TR $)^{2}+$ estimated RAP, where $\mathrm{TR}=$ tricuspid regurgitation, $\mathrm{RAP}=$ right atrial pressure.

\section{Statistical analyses}

Patient characteristics and outcomes were summarized by using frequency and percentage or median and $25^{\text {th }}$ and $75^{\text {th }}$ percentiles. Linear regression was used to assess factors independently and in multivariable models for $6 \mathrm{MWD}$, log-transformed BNP, Borg dyspnea scale, RVSP, RAP, cardiac output, and cardiac index. For aldosterone and BNP levels, data was adjusted for age, gender, BMI, idiopathic PAH (IPAH), and for mineralocorticoid receptor (MR) blocker status. Logistic regression was used to assess right ventricular hypertrophy/ dilation $(\mathrm{RVH} / \mathrm{D})$ and pericardial effusion. Odds ratios for potential factors associated with $\mathrm{RVH} / \mathrm{D}$ and pericardial effusion were determined. Note that the association was explored independently for each variable listed. Cox proportional hazards model was used to assess time to death. Kaplan-Meier analysis for time-to-death by aldosterone and BNP levels was undertaken. Both aldosterone and BNP were $\log$-transformed due to the skewed nature of their distributions. This analysis did not account for multiple comparisons. Due to the large number of outcomes investigated, a significance level of 0.01 was used for the multivariable models

\section{Results}

\section{Baseline patient characteristics}

A total of 182 patients were screened and 125 patients with $\mathrm{PAH}$ make up the study cohort (Figure 1). Of the 125 patients with diagnostic group $1 \mathrm{PAH}, 89 \%$ were females and $62 \%$ were Caucasian (Table 1 ).

\section{Biomarker, clinical and hemodynamic parameters}

The median aldosterone level was $9.9 \mathrm{pg} / \mathrm{ml}$ (25th-75th percentile: $4.1 \mathrm{pg} / \mathrm{ml}, 27.1 \mathrm{pg} / \mathrm{ml}$ ) and median BNP level was $67.5 \mathrm{pg} / \mathrm{ml}$ (25th-75th percentile: $31 \mathrm{pg} / \mathrm{ml}, 225 \mathrm{pg} / \mathrm{ml}$ ) in the PAH patients (Figure 2). The 6MWD was 69 meters higher in IPAH patients compared to connective tissue disease and congenital heart disease associated $\mathrm{PAH}(\mathrm{P}=0.022)$. Additionally, the 6MWD decreased with increasing age $(\mathrm{P}=0.014)$. Both the unadjusted and adjusted data showed that the aldosterone levels were not associated with 6MWD (Figure 3A), Borg dyspnea scale score (Figure 3B), BNP levels, RVSP (Figure 3C), cardiac output, presence of pericardial effusion or RVH/D. The unadjusted results showed that RAP increased for those on MR blocker $(\mathrm{p}=0.012)$, loop diuretics $(\mathrm{p}=0.04)$, and with increasing BMI $(\mathrm{p}=0.008)$, and with increasing

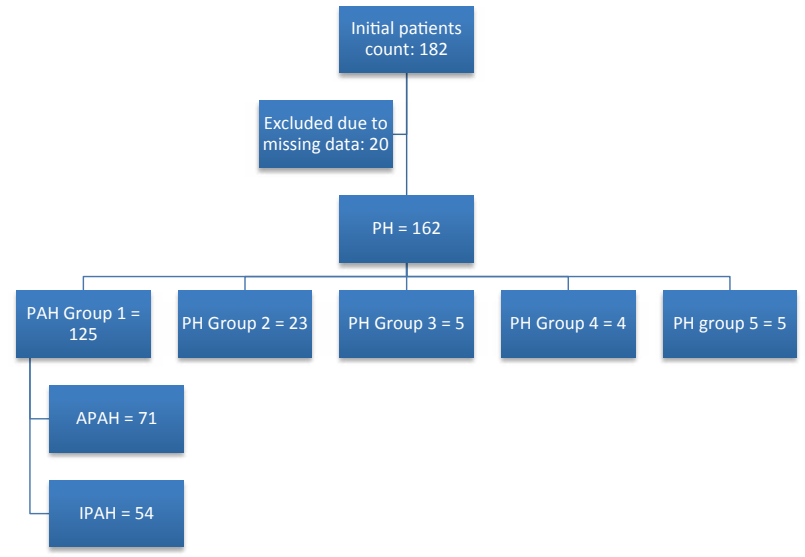

Figure 1: Outline of Patients included in the Study.

\begin{tabular}{|c|c|}
\hline Variables & \\
\hline Age (years), Mean (SD) & $51(14)$ \\
\hline BMI (kg/m ), Mean (SD) & $27.3(7.0)$ \\
\hline Male, $\mathrm{N}(\%)$ & $14(11 \%)$ \\
\hline Caucasian, N(\%) & $53(62 \%)$ \\
\hline Aldosterone (pg/ml), Median (25th, 75th) & $9.9(4.1,27.1)$ \\
\hline BNP (pg/ml), Median (25th, 75th) & $67.5(31,225)$ \\
\hline LVEF (\%), Median (25th, 75th) & $65(59,65)$ \\
\hline LA Dilation, $\mathrm{N}(\%)$ & $17(17 \%)$ \\
\hline \multicolumn{2}{|l|}{ Medications: } \\
\hline MR blocker, N (\%) & $58(49 \%)$ \\
\hline Loop diuretics, N (\%) & $55(46 \%)$ \\
\hline CCB, N (\%) & $24(20 \%)$ \\
\hline Digitalis, N (\%) & $65(54 \%)$ \\
\hline \multicolumn{2}{|l|}{ Echocardiographic data: } \\
\hline RVSP on TTE (mm Hg), Mean (SD) & $83(26.2)$ \\
\hline RAP on TTE (mm Hg), Mean (SD) & $12.3(5.2)$ \\
\hline Cardiac output (L/min), Mean (SD) & $4.5(1.3)$ \\
\hline Cardiac index (L/min/m2), Mean (SD) & $2.69(0.75)$ \\
\hline Pericardial Effusion, N (\%) & $24(23 \%)$ \\
\hline $\mathrm{RVH} / \mathrm{D}, \mathrm{N}(\%)$ & $67(74 \%)$ \\
\hline Six-minute walk distance, Mean (SD) & $359(114)$ \\
\hline Borg Dyspnea Scale, Mean (SD) & $2.82(1.85)$ \\
\hline Death, N (\%) & $24(19 \%)$ \\
\hline
\end{tabular}

Data presented as number $(N)$ and percentage $(\%)$ or median $25^{\text {th }}-75^{\text {th }}$ percentile or mean $\pm \mathrm{SD}$ as indicated. APAH-CTD, connective tissue disease associate PAH, APAH-CHD, congenital heart disease associated PAH; CCB, calcium channe blocker; IPAH, idiopathic pulmonary arterial hypertension; LA, left atrial; MR blocker, mineralocorticoid receptor blocker; RAP, right atrial pressure. RVSP, righ ventricular systolic pressure; RVH/D, right ventricular hypertrophy/dilation; TTE, transthoracic echocardiogram.

Table 1: Baseline Clinical Characteristics of Diagnostic Group 1 PAH patients.

BNP and aldosterone levels $(p=p=0.01$ and $p=0.034$ respectively). This association between RAP and aldosterone levels was lost in the adjusted data; however, after including an interaction $(\mathrm{p}=0.001)$ with MR blocker, an association between aldosterone level and RAP was noted (Coef. $=2.88,95 \mathrm{CI}$ : $1.19,4.56, \mathrm{p}=0.001$, Figure 3E). Namely, for those not taking MR blocker, for a 50\% increase in aldosterone level the average RAP decreased by $0.52(\mathrm{p}=0.055)$; and for those taking the MR blocker, the average RAP increased by $0.64(\mathrm{p}=0.004)$. In this cohort, $49 \%$ of the PAH patients were on a MR blocker.

The BNP levels were higher in males $(\mathrm{p}=0.042)$ and for those on MR blocker $(\mathrm{p}=0.019)$ and calcium channel blocker $(\mathrm{CCB})(\mathrm{p}=0.006)$ 


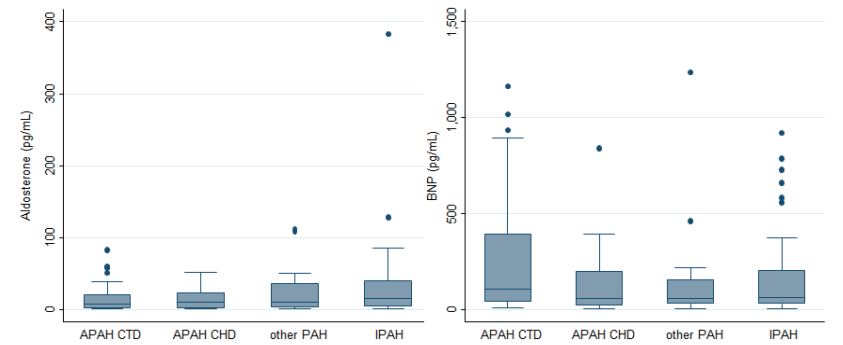

The median aldosterone level was $9.9 \mathrm{pg} / \mathrm{ml}(25 \mathrm{th}-75$ th percentile: $4.1 \mathrm{pg} / \mathrm{ml}$, $27.1 \mathrm{pg} / \mathrm{ml}$ ) and median BNP level was $67.5 \mathrm{pg} / \mathrm{ml}$ (25th-75th percentile: 31 $\mathrm{pg} / \mathrm{ml}, 225 \mathrm{pg} / \mathrm{ml}$ ) in PAH patients.

Figure 2: Median aldosterone and BNP levels in PAH patients.

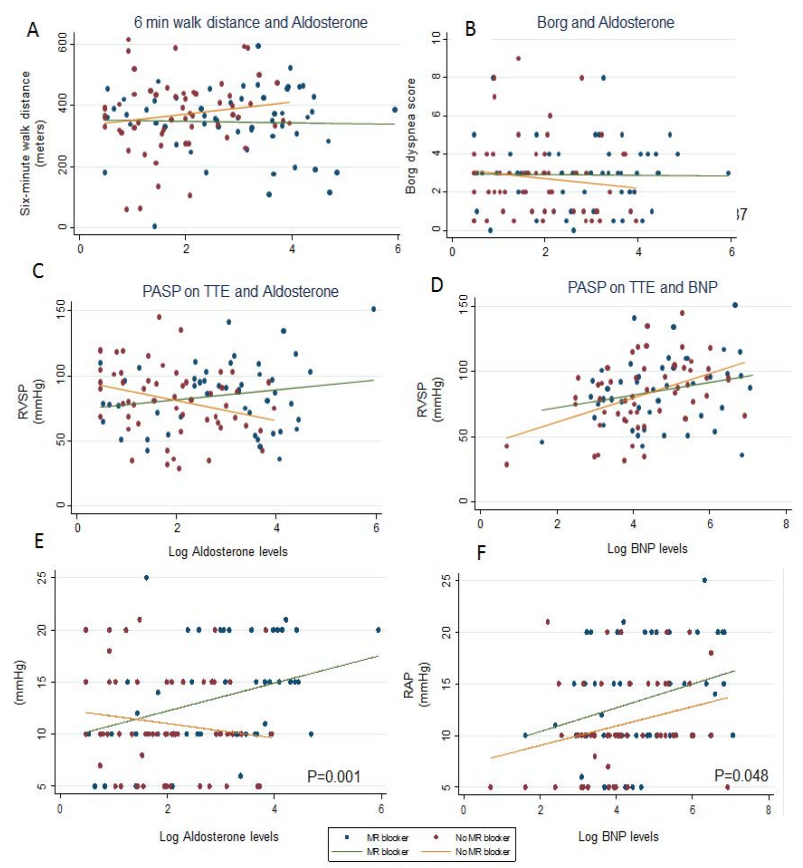

Figure 3: Scatter plots of log-aldosterone and log-BNP levels and clinical parameters for adjusted data. Six-minute walk distance and aldosterone levels. B. Borg dyspnea score and aldosterone levels. C. Right ventricle systolic pressure and aldosterone levels. D. Right ventricle systolic pressure and BNP levels. E. Right atrial pressure and aldosterone levels. F. Right atrial pressure and BNP levels. Figures are colored coded for MR receptor blocker status (blue, patients taking MR blocker; and red, patients not taking MR blocker). RAP, right atrial pressure; RVSP, right ventricular systolic pressure.

BNP levels decreased with increasing BMI $(\mathrm{p}=0.002)$. BNP did not associate with aldosterone levels (0.706). However, the adjusted data demonstrated that CI negatively associated with BNP (Coef. $=-0.16$, 95CI: $-0.31,-0.01, \mathrm{p}=0.04)$. Furthermore BNP also associated with RVSP (Coef. $=5.64,95 \mathrm{CI}$ : 1.27, 10.02, $\mathrm{p}=0.012$; (Figure 3D) and RAP (Coef. $=0.73$, 95CI: 0.01, $1.45 \mathrm{p}=0.048$; (Figure 3F). In addition, the odd of having a pericardial effusion was higher if BNP was elevated (odds ratio $1.65,95 \mathrm{CI}=1.13,2.4, \mathrm{p}=0.01$ ) whereas this was not noted with aldosterone. Neither aldosterone nor BNP levels were associated with the odds of having RVH/D.

\section{Time to death}

results show that increased BNP levels $(\mathrm{p}<0.001)$, males $(\mathrm{p}=0.034)$, and patients not on CCB $(\mathrm{p}=0.038)$ were associated with an increased hazard of death. After adjustment for a $50 \%$ increase in BNP the hazard of death increased by $1.36(\mathrm{p}<0.001)$.

\section{Discussion}

In this study, elevated BNP levels but not aldosterone levels confer increased mortality in PAH patients. Furthermore, RAP associated with higher aldosterone levels in patients being treated with a MR blocker. Although hyperaldosteronism was associated with higher levels of RAP, it did not associate with other hemodynamic parameter or with mortality. This relationship was probably observed because of the relationship between cardiac output and RAP [15]. In addition, patients in this cohort were established PAH patients on PAH medications and

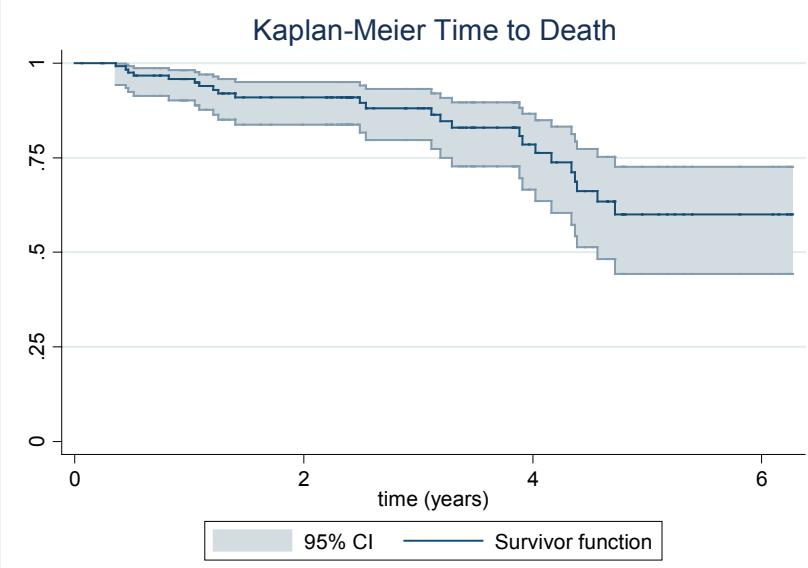

Figure 4: Kaplan-Meier survival graph for the studied cohort. The $75^{\text {th }}$ survival percentile for the studied cohort was 4.1 years $(95 \% \mathrm{Cl}: 3.2,4.7)$.

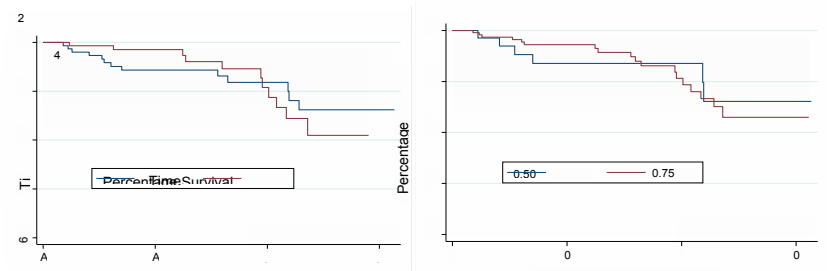

Figure 5: Kaplan-Meier survival graph based on median and normal laboratory aldosterone levels. The normal reference level for aldosterone was less than $31.0 \mathrm{ng} / \mathrm{dL}$ under unspecific condition.

Mean follow up time of $34 \pm 19$ (1-75) months was observed, at which point 24 out of the 125 patients were deceased (19\%). The $75^{\text {th }}$ survival percentile was 4.1 years (95\% CI: 3.2, 4.7). Kaplan Meier survival curve for the overall studied $\mathrm{PAH}$ population is presented in Figure 4. By log-rank statistics there was not a statistical difference between the survival when patients were categorized by median aldosterone levels $(\mathrm{p}=0.9135)$ or when divided by normal aldosterone levels ( $\mathrm{p}=0.9764)$ (Figure 5). However, there was a significant difference in survival based on BNP levels divided by median $(p=0.0004)$ and by low, mid and high BNP levels $(\mathrm{p}<0.001)$ (Figure 6$)$. The unadjusted 

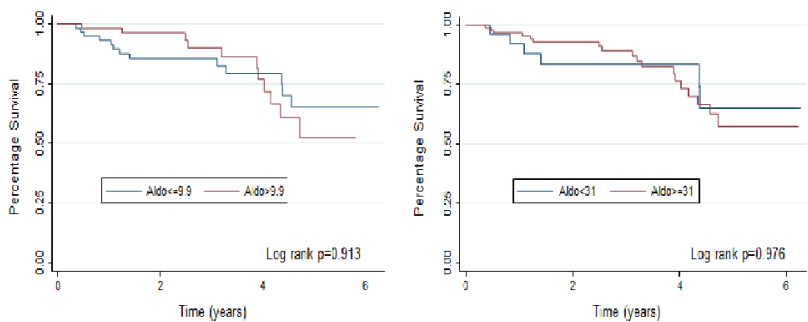

Figure 6: Kaplan-Meier survival graph based on median, and low, mid and high BNP levels. Normal BNP level range was $0-100 \mathrm{pg} / \mathrm{ml}$ and BNP was divided into 3 groups according to the REVEAL Registry Score Calculator: low BNP ( $\leq 50 \mathrm{pg} / \mathrm{mL}$ ), mid-level BNP (51 to $180 \mathrm{pg} / \mathrm{mL}$ ), and high BNP $(>180 \mathrm{pg} / \mathrm{mL})$.

the biomarker sample was drawn from a peripheral vein at the time of their clinic appointment rather than during heart catheterization.

Previous studies have explored the contribution of RAAS in PAH. For example, De Man et al demonstrated elevated levels of renin, angiotensin I and angiotensin II in PAH patients [2]. These levels were associated with increased risk of death, lung transplantation and disease progression defined by decrease in 6MWD [2]. Our study results were to the contrary in terms of elevated aldosterone levels not being associated with worse outcome. In a small study, Maron et al. documented elevated plasma aldosterone levels in $18 \mathrm{PAH}$ patients as compared to 5 control patients undergoing dyspnea evaluation [10]. In this study, a sub group of treatment-naive PAH patients showed that the aldosterone levels were positively correlated with pulmonary vascular resistance (PVR) and transpulmonary gradient, and negatively correlated with cardiac output. Authors suggested a cardiopulmonary hyperaldosteronism profile of PAH patients was indicative of worse disease. In another study of 21 PAH patients, indices of RAAS activation including aldosterone, angiotensin converting enzyme, plasma rennin activity, angiotensin II and vasopressin levels were found to be elevated [14]. These levels were higher in patients with mean pulmonary artery pressure of $60 \mathrm{~mm} \mathrm{Hg}$ [14]. In another study evaluating subjects with High Altitude Pulmonary Hypertension showed elevated plasma renin activity that correlated with PVR [15]. Our study results show that increased aldosterone levels were associated with higher RAP obtained from non-invasive testing. Unfortunately, invasive hemodynamic data was not available in relation to the biomarker testing. Larger studies will need to be done to further explore this relationship.

BNP, or brain natriuretic peptide, is a known biomarkers in PAH and elevated levels have been associated with poor outcome in PAH [16]. Natriuretic peptides are released by the heart to counteract myocardial tension and increased intravascular volume [17]. High levels of natriuretic peptide in circulation indicates raised atrial and pulmonary capillary wedge pressures, reduced ventricular systolic and diastolic function, presence of left ventricular index, and positively correlate with WHO functional class, pulmonary vascular resistance and RAP in PAH patients $[18,19]$. In previous studies, BNP levels were found to be elevated among patients with left ventricular systolic dysfunction, and thus it is a recognized marker for cardiovascular disease due to left heart failure $[19,20]$. As in our study, Borg dyspnea scale, RVSP, RAP, and pericardial effusion, all have been shown to increase with increasing BNP values. In addition, cardiac output decreased with higher BNP values [21]. Our study results showed that higher BNP levels were associated with increase in risk of death, whereas no relationship was found between aldosterone and worsen clinical outcomes.
In a study by Deboeck et al., 6MWD predicted not just survival but also time to clinical worsening [22]. Six-minute walk distance has been proven to be a good predictor of clinical worsening in $\mathrm{PAH}$ and of mortality $[23,24]$. It has been shown that IPAH patients have a better 6MWD than those diagnosed with associated PAH [22]. Our study reinforced this finding, as better $6 \mathrm{MWD}$ was seen in patients with IPAH than those with associated PAH.

Recent clinical research by Tsutamoto et al has shown that administration of MR antagonist, spironolactone, together with an endothelin type-A receptor antagonist resulted in lower BNP levels, better 6MWD, and improvement in WHO functional class [25] Spironolactone administration usually results in mild natriuresis that may contribute to improved BNP levels $[10,26]$. Interestingly, our data found an association between aldosterone levels and RAP, in patients who were on the MR blocker. Studies such as Randomized Aldactone Evaluation Study (RALES) and Eplerenone Post-Acute Myocardial Infarction Heart Failure Efficacy and Survival Study (EPHESUS) have shown that MR blockers improved survival in patients with congestive heart failure $[7,27]$. Spironolactone has proven to be beneficial in patients with congestive heart failure. The usefulness of the MR blockers would suggest increased levels of aldosterone in these patients. However, data revealed that MR antagonists improve survival even in those with normal circulating aldosterone levels [28]. In animal model of $\mathrm{PH}$, spironolactone prevented the increase of right ventricular (RV) systolic pressure, pulmonary arterial muscularization, and RV fibrosis, all of which lead to PAH [8]. In our study, we explored whether circulating aldosterone levels are related to worse disease and/or increased mortality in PAH. Interestingly, RAP was higher in patients on a MR blocker and was lower in patients who were not on a MR blocker. This seemingly contradictory finding may suggest that patient on a MR blocker are sicker to begin with or have a worse disease. MR blockers are routinely used as a diuretic in PAH patients. An ongoing clinical trial of spironolactone versus placebo in PAH will help to define the usefulness of MR blocker in this disease [clinicaltrials.gov; NCT01468571].

\section{Study Limitations}

Limitations to the current study include missing data and the hemodynamic data are collected by a transthoracic echocardiogram. In addition, aldosterone level was measured once at baseline and follow up aldosterone levels were not available. Despite these limitations, the number of eligible participants for mortality analyses strengthens our results.

\section{Acknowledgements}

Authors wish to thank Ms. Janice Brister for editorial support. This work was funded in part by National Heart, Lung, and Blood Institute Grant K23 HL093214 to Z. Safdar.

\section{References}

1. Humbert M, Morrell NW, Archer SL, Stenmark KR, MacLean MR, et al. (2004) Cellular and molecular pathobiology of pulmonary arterial hypertension. J Am Coll Cardiol 43: 13S-24S

2. de Man FS, Tu L, Handoko ML, Rain S, Ruiter G, et al. (2012) Dysregulated renin-angiotensin-aldosterone system contributes to pulmonary arterial hypertension. Am J Respir Crit Care Med 186: 780-789.

3. Struthers AD (2004) Aldosterone in heart failure: pathophysiology and treatment. Curr Heart Fail Rep 1: 171-175.

4. Zannad F, Alla F, Dousset B, Perez A, Pitt B (2000) Limitation of excessive extracellular matrix turnover may contribute to survival benefit of spironolactone therapy in patients with congestive heart failure: insights from the randomized aldactone evaluation study (RALES). Rales Investigators. Circulation 102 


$$
\text { 2700-2706. }
$$

5. Schmidt BM, Schmieder RE (2003) Aldosterone-induced cardiac damage: focus on blood pressure independent effects. Am J Hypertens 16: 80-86.

6. de Man FS, Handoko ML, Guignabert C, Bogaard HJ, Vonk-Noordegraaf A (2013) Neurohormonal axis in patients with pulmonary arterial hypertension: friend or foe? Am J Respir Crit Care Med 187: 14-19.

7. Pitt B, Zannad F, Remme WJ, Cody R, Castaigne A, et al. (1999) The effect of spironolactone on morbidity and mortality in patients with severe heart failure. Randomized Aldactone Evaluation Study Investigators. N Engl J Med 341: 709 717.

8. Brown NJ (2005) Aldosterone and end-organ damage. Curr Opin Nephrol Hypertens 14: 235-241.

9. Tomaschitz A, Pilz S, Ritz E, Grammer T, Drechsler C, et al. (2011) Association of plasma aldosterone with cardiovascular mortality in patients with low estimated GFR: the Ludwigshafen Risk and Cardiovascular Health (LURIC) Study. Am J Kidney Dis 57: 403-414.

10. Maron BA, Opotowsky AR, Landzberg MJ, Loscalzo J, Waxman AB, et al (2013) Plasma aldosterone levels are elevated in patients with pulmonary arterial hypertension in the absence of left ventricular heart failure: a pilot study. Eur J Heart Fail 15: 277-283.

11. Maron BA, Waxman AB, Opotowsky AR, Gillies H, Blair C, et al. (2013) Effectiveness of spironolactone plus ambrisentan for treatment of pulmonary arterial hypertension (from the [ARIES] study 1 and 2 trials). Am J Cardiol 112 720-725.

12. Benza RL, Gomberg-Maitland M, Miller DP, Frost A, Frantz RP, et al. (2012) The REVEAL Registry risk score calculator in patients newly diagnosed with pulmonary arterial hypertension. Chest 141: 354-362.

13. Benza RL, Miller DP, Gomberg-Maitland M, Frantz RP, Foreman AJ, et al. (2010) Predicting survival in pulmonary arterial hypertension: insights from the Registry to Evaluate Early and Long-Term Pulmonary Arterial Hypertension Disease Management (REVEAL). Circulation 122: 164-172.

14. Martyniuk TV, Chazova IE, Masenko VP, Volkov VN, Belenkov lu N (1998) [Activity of renin-angiotensin-aldosterone system (RAAS) and vasopressin level in patients with primary pulmonary hypertension]. Ter Arkh 70: 33-36.

15. Batyraliev TA, Kudaiberdieva GZ, Sodanbekova JK, Aikimbaev KS, Gunal Z, et al. (1998) Correlation of Atrial Natriuretic Factor and Renin-Aldosterone System With Chronic Pulmonary Hypertension Among Residents in a High Altitude. Int J Angiol 7: 271-274.

16. Nagaya N, Nishikimi T, Okano Y, Uematsu M, Satoh T, et al. (1998) Plasma brain natriuretic peptide levels increase in proportion to the extent of right ventricular dysfunction in pulmonary hypertension. J Am Coll Cardiol 31: 202-
208.

17. Doust JA, Pietrzak E, Dobson A, Glasziou P (2005) How well does B-type natriuretic peptide predict death and cardiac events in patients with heart failure: systematic review. BMJ 330: 625.

18. Sagnella GA (1998) Measurement and significance of circulating natriuretic peptides in cardiovascular disease. Clin Sci (Lond) 95: 519-529.

19. Leuchte HH, Holzapfel M, Baumgartner RA, Ding I, Neurohr C, et al. (2004) Clinical significance of brain natriuretic peptide in primary pulmonary hypertension. J Am Coll Cardiol 43: 764-770

20. Krüger S, Graf J, Kunz D, Stickel T, Hanrath P, et al. (2002) brain natriuretic peptide levels predict functional capacity in patients with chronic heart failure. Am Coll Cardiol 40: 718-722.

21. Benza RL, Gomberg-Maitland M, Miller DP, Frost A, Frantz RP, et al. (2012) The REVEAL Registry risk score calculator in patients newly diagnosed with pulmonary arterial hypertension. Chest 141: 354-362.

22. Deboeck G, Scoditti C, Huez S, Vachiéry JL, Lamotte M, et al. (2012) Exercise testing to predict outcome in idiopathic versus associated pulmonary arterial hypertension. Eur Respir J 40: 1410-1419.

23. Miyamoto S, Nagaya N, Satoh T, Kyotani S, Sakamaki F, et al. (2000) Clinica correlates and prognostic significance of six-minute walk test in patients with primary pulmonary hypertension. Comparison with cardiopulmonary exercise testing. Am J Respir Crit Care Med 161: 487-492.

24. Sitbon O, Humbert M, Nunes H, Parent F, Garcia G, et al. (2002) Long term intravenous epoprostenol infusion in primary pulmonary hypertension: prognostic factors and survival. J Am Coll Cardiol 40: 780-788.

25. Tsutamoto T, Wada A, Maeda K, Mabuchi N, Hayashi M, et al. (2001) Effect of spironolactone on plasma brain natriuretic peptide and left ventricula remodeling in patients with congestive heart failure. J Am Coll Cardiol 37: 1228 1233

26. Rousseau MF, Gurné O, Duprez D, Van Mieghem W, Robert A, et al. (2002) Beneficial neurohormonal profile of spironolactone in severe congestive hear failure: results from the RALES neurohormonal substudy. J Am Coll Cardiol 40: 1596-1601.

27. Pitt B, White H, Nicolau J, Martinez F, Gheorghiade M, et al. (2005) Eplerenone reduces mortality 30 days after randomization following acute myocardia infarction in patients with left ventricular systolic dysfunction and heart failure. $J$ Am Coll Cardiol 46: 425-431.

28. Funder JW (2005) RALES, EPHESUS and redox. J Steroid Biochem Mol Bio 93: $121-125$ 